\title{
Study of the influence of Structural parameters of Common Rail Injector on the Ejecting Performance
}

\author{
$\mathrm{Hu}$ Yan \\ School of Mechanical Electronic and Control Engineering of Beijing Jiao tong University Beijing 100044, China
}

\begin{abstract}
High-pressure common rail injector is one of the most important components of the fuel injection system, and its performance will directly affect the engine combustion process. As the high-pressure common rail injector complex structure and the structure parameters which affect the ejecting performance are numerous. In order to understand the trend and impact of effect of the so many parameters, the simulation is necessary to identify the key structure parameters and operating parameters which affect the ejecting performance, and understand how these key parameter in the injector design of the selection principle. Variable parameters research is carried out based on the simulation model of the injector key structural parameters to analyze the influences of dynamic performance, such as response characteristic and fuel injection law,and indicate the principles of the injector design.
\end{abstract}

Keywords-High-pressure common rail injector; structure parameters; ejecting performance; Hydsim

\section{INTRODUCTION}

Since put into practical application from the end of the twentieth Century, the injection of electronically controlled high pressure common rail system because of its high average effective injection pressure, flexible timing control, the injection pressure is not affected by the speed limit and realize the pre injection, post injection, and even multiple injection has been accepted and spread vary widely. And the traditional pump pipe nozzle system, high pressure common rail fuel injection system to fuel metering process and injection timing, the two most important features from the high-pressure pump to the fuel injector. So the complexity of structure, working process of common rail injector has nontraditional injector comparable. As the most complex, high pressure common rail systems in the core parts of the work, the working performance of common rail injector work performance will directly affect the entire highpressure common rail system, which had great influence on the engine performance. Therefore, it is necessary to research on common rail injector.

This paper uses AVL company's Hydsim software, taking a certain type of common rail injector as a prototype for simulation study, explore the injector control chamber volume, inlet orifice, out let orifice, pressure regulating spring, valve chamber, nozzle hole diameter and number of nozzles, flow coefficient on injection performance, analyzes the cause of influence, provides the theory basis for the development of new type injector.

\section{THE ESTABLISHMENT OF CALCULATION MODEL}

A. Common rail injector structure and working process

Injector of common rail is controlled by the electromagnetic valve, the control piston parts and moving parts and injection nozzle matching parts. Its working process is when the solenoid valve is not energized, the control valve is connected with the solenoid armature in the closed state, high pressure common rail pipe pressure through an oil inlet hole and role in the control of the piston top and nozzle, the control piston top surface area is larger than the nozzle area of pressure, force a preloaded spring plus, the needle cannot be lifted up. When the solenoid valve is energized, the control valve under the action of the electromagnetic force to overcome the spring force to open, open the oil orifice. Because the oil flow, pressure loss through the oil inlet orifice after the pressure drop in the control room, now the role in nozzle pressure on the surface of the pressure does not change. When the fluid pressure valve is greater than the control piston by liquid pressure and preload spring force, and when the valve opening, injector, fuel injectors. Solenoid valve power, under the action of the spring force, the control valve closed quickly, act to control the piston top surface fluid pressure increases, so that the needle valve, fuel injection stop. ${ }^{[1],[2]}$

\section{B. The establishment of calculation model}

Based on the structure and the working process of common rail injector based, simulation software Hydsim to build the simulation model. Due to considering only the structural parameters of injector, so the electromagnetic characteristics of the solenoid valve made the corresponding simplified, only consider the driving characteristics. In the modeling, the injector according to the requirements into pipe, volume chamber, throttle valve, piston, valve and spring and other basic unit, according to the calculation equation function of each unit to each other, connected and combined calculation model by means of hydraulic, mechanical and special way. Various model parameters calculated according to actual parameters and operating conditions of the fuel injection system, the basic equation of viscous fluid simulation available one-dimensional unsteady flow equation. The main equation: 
The continuity equation: $\frac{\partial \rho}{\partial t}+\frac{\partial \rho}{\partial x}+\rho \frac{\partial u}{\partial x}=0$

The momentum

$\frac{\partial u}{\partial t}+\frac{\partial u}{\partial x}+\frac{1}{\rho} \frac{\partial p}{\partial x}=-\sum f_{i}+\frac{4}{3} \mu \frac{\partial^{2} u}{\partial x^{2}}$

equation

:

Fuel oil compressibility equation: $d \rho=-\frac{E}{V} d V$

Flow equation: $Q=C_{d} A \sqrt{\frac{2 \Delta p}{\rho}}=\frac{C_{d} \pi d^{2}}{4} \sqrt{\frac{2 \Delta p}{\rho}}$

The force balance equation: $m \frac{d^{2} x}{d t^{2}}=\sum f$

Among them, $u$ as the fuel flow rate, $\rho$ as the fuel density, $p$ as the pressure, $\mu$ as the dynamic viscosity, $\sum f_{i}$ as the force acting on the fluid flow resistance of the fuel, $E$ as the bulk modulus, $V$ as the fluid volume, $Q$ as the flow, $d$ as the aperture, $\Delta p$ as the pressure difference, $C_{d}$ as the flow coefficient, $A$ as the flow cross-sectional area, $\sum f$ as the forces on the moving component, $m$ as moving parts mass. ${ }^{[5]}$

\section{EFFECTS OF COMMON RAIL INJECTOR STRUCTURE PARAMETERS ON INJECTION CHARACTERISTICS OF THE SYSTEM}

\section{A. Effect of pressure control chamber part parameters}

The control effect of the piston top control chamber volume.

In the pressure range of high pressure common rail system, can not be ignored in the compressibility of fuel, the size of the volume control room and is connected with the control piston, in a large extent will affect the control of indoor pressure, will also affect the control piston movement speed and nozzle needle

valve connected, thus affecting the needle the effective opening time, ultimately affect the fuel injection quantity. When the control chamber volume is larger, the electromagnetic valve is opened and closed, the control room pressure drop and pressure build up process is relatively slow, needle movement speed is relatively slow, there is hysteresis; and because the pressure fluctuation and needle valve solenoid valve closed control room have to close the process pressure fluctuations will make the needle valve lift two times in the valve cavity, have two times of injection. Control chamber volume is small, the electromagnetic valve is opened and closed, the control room pressure decreased rapidly and elevated rapid response, needle valve, open and quickly off the oil simply. But because the smaller volume of control chamber, pressure fluctuation generated electromagnetic valve is closed to control the indoor pressure fluctuation is strong. ${ }^{[3][7]}$
Figure 1 respectively show the other parameters unchanged, the effect of control chamber volume lift and injection rate on the control chamber pressure, needle valve. $44 \mathrm{~mm}^{3}, 64 \mathrm{~mm}^{3}, 84 \mathrm{~mm}^{3}$ were collected from three control chamber volume.
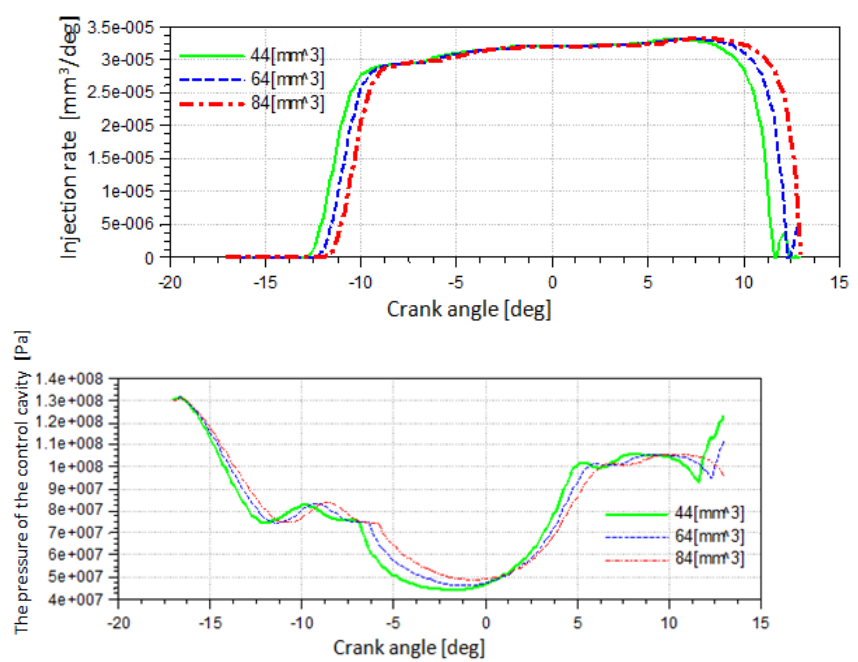

Figure1 Effect of control chamber volume

As can be seen, change control chamber volume shape effect on fuel injection characteristic curve is not significant, but makes the fuel injection law curve to produce a translation, resulting in slower response; at the same time we can also see the control cavity volume mainly the influence of injection starting point, oil cut-off time roughly the same, which will affect the entire injection duration, eventually led to the injection volume change. Therefore, the control cavity volume increases, the fuel injection timing delay resulting injection duration shortened, fuel injection quantity decreases, when the control chamber volume is too large, the injection speed of response can be reduced, effects of reinjection. Therefore, under the same other structure parameters, the injection quantity will increase along with the control cavity volume decreased.

\section{EFFECTS OF INLET, OUTLET ORIFICE PARAMETERS}

Change the fuel pressure in the control room control the start and stop fuel injector, throttle flow area the size directly affects the fuel pressure in the control room change. Therefore, the oil hole diameter directly affects the size of the opening and closing process of injector valve, thus affecting the fuel injection law. Because, out of the oil hole length is small, the main factor to determine the flow is the aperture, the common rail injector working principle knowable, only to meet the oil hole diameter is less than the amount of oil hole aperture case, control cavity to normal pressure relief, the needle valve can be raised properly, injector to the normal fuel injection. Figure 2 is the oil hole diameter is less than the amount of oil hole diameter of the premise, the oil inlet hole diameter is $0.28 \mathrm{~mm}$, different import oil hole diameter of $0.29 \mathrm{~mm}, 0.30$ 
$\mathrm{mm}, 0.32 \mathrm{~mm}$, and $0.34 \mathrm{~mm}$, and analyzes its influence on the fuel injection characteristics.
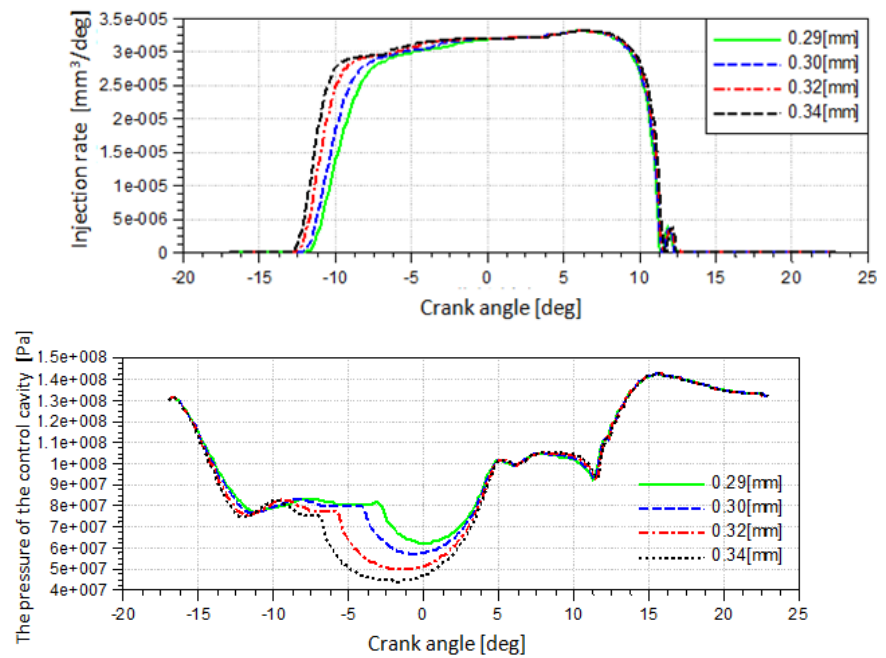

Figure2 Effects of inlet, outlet orifice parameters

\section{A. Effect of needle valve part parameters}

Effect of needle valve pressure regulating spring preload and stiffness.

In the high pressure common rail system, the needle valve, needle valve on the hydraulic control cavity chamber and a pressure chamber of the force and spring force to achieve the opening and closing valve. Injector needle valve pressure regulating spring's role is to ensure that in the common rail pressure built up before the needle valve to overcome the cylinder pressure and closed, at the same time guarantee in the control chamber pressure drops to the back pressure valve can rise before. The fuel pressure is high, the needle valve spring stiffness and preload increases the injector minimum closed cycle decreas ed slightly, while in the low fuel pressure, needle valve spring stiffness and preload on the injector minimum affected closed cycle. ${ }^{[4]}$

Figure 3 for the different needle valve pressure regulating spring preload needle valve shape response characteristics and the injection pattern. In the other parameters unchanged, select 4 groups of preload value: $15 \mathrm{~N}, 40 \mathrm{~N}, 80 \mathrm{~N}, 120 \mathrm{~N}$,calculate the needle lift and injection law.
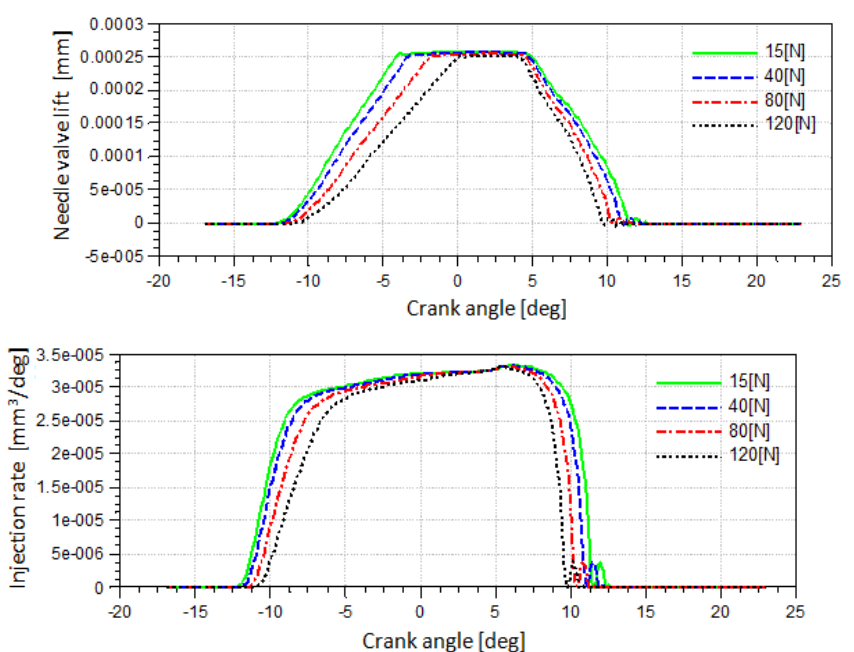

Figure3 Effect of needle valve pressure regulating spring preload

As can be seen, in the control parameters were identical, with the increase of the pressure adjusting spring preload, fuel injection timing delay and oil break ahead of time, the injection duration and injection rate reduced peak is decreased, resulting in reduced fuel injection quantity. Although the increase of nozzle pressure regulating spring preload can make the fuel injection law has some improvement, but with a loss of injection pressure and injection quantity at the expense of. But the preload is too large will cause the needle in the process of spraying downward movement, even sit close the injection, which is seriously affecting the injection process. Valve spring preload set in the injector needle valve is ejected in the non can reach the critical stress balance, valve spring preload reasonable can effectively avoid artificial two injection control, in the injector needle valve, in order to enable the rapid rising and falling, the good control of injection, reasonable selection of pre tightening force is particularly critical.

\section{B. Effects of nozzle parameters}

Effect of nozzle hole diameter and number.

Injector nozzle is fuel is sprayed into the combustion chamber, in the common rail pressure and injection duration under certain conditions, the total cross-sectional area of the orifice size directly determines the cycle fuel injection quantity. At the same time, in order to obtain better atomization effect, need to narrow orifice diameter, at the request of cycle fuel injection quantity invariable situation, only by increasing orifice numbers reach

the requirements. Therefore, the correct choice of nozzle hole number and diameter is the optimization of diesel spray and combustion matching key. In order to improve the atomization of fuel injection system, the nozzle structure tends to increase the number of holes, decreasing the hole diameter, and will be widely adopted in small volume of a pressure chamber, to reduce $\mathrm{HC}$ and $\mathrm{PM}$ emissions ${ }^{[6]}$. But because the processing 
technology and the structure, number of nozzle holes can not increase too much. Figure 4 for the other parameters unchanged, the flow coefficient under the condition of $=0.6422$, the selected number of holes is 6 , the injection pattern and pressure of nozzle orifice diameter of fig.
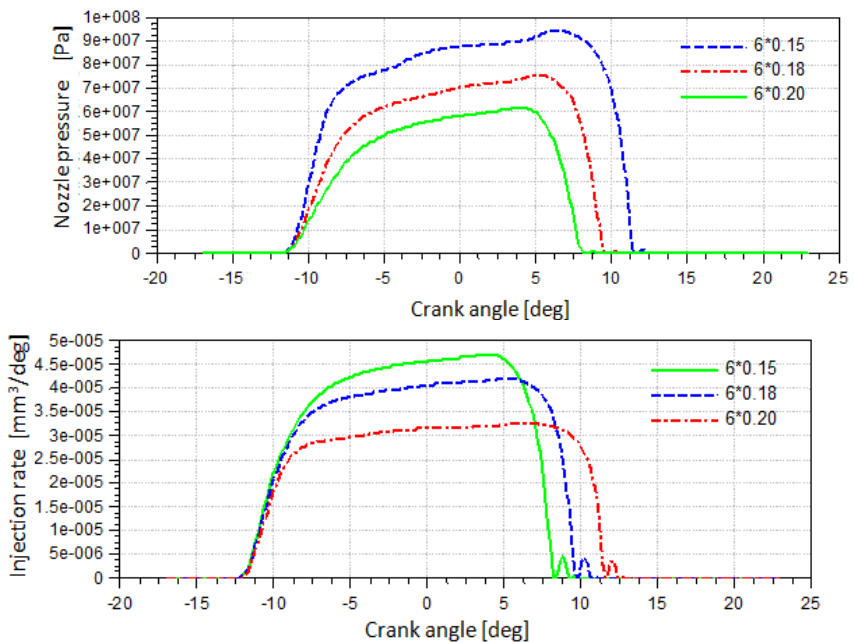

Figure4 Effect of nozzle hole diameter and number

From the figure, with the nozzle hole diameter increased, decreased orifice throttling effect, so the nozzle pressure peak decreases; at the same time in the system of fuel injection quantity is kept constant, the injection duration corresponding to shorten. Ibid., through the nozzle hole number variable parameter study found that, along with the increase of nozzle hole number, the total flow area of nozzle, nozzle pressure peak decreases, and the injection rateis increased and peak; in the condition of invariable system of fuel injection quantity, injection duration corresponding to shorten. Choice of nozzle hole number and diameter of the nozzle flow coefficient principle is: can not be too large, otherwise unable to process the nozzle to ${ }^{[8]}$. According to this point and then according to the type of engine used to decide the number of small pore size of porous, or large aperture less number of holes. For the diesel engine for vehicle, due to emissions is more demanding, often using small aperture injector fuel atomization, to get better effect, to reduce $\mathrm{HC}$ and $\mathrm{PM}$ emissions.

\section{CONCLUSION}

Through the analysis of simulation results, the following conclusion:

(1), into the oil throttle aperture size has an important effect on the performance of the system, the selection of the parameters is not only ensure the needle valve can open quickly, at the same time to ensure that cannot cause the two injection.

(2) establish the size effect of control cavity volume to control the pressure, we should try to reduce, in order to ensure the speed of response of injector.

(3) the needle valve pressure regulating spring preload and stiffness parameters of the fuel injection law influence is not very big, but still need to be carefully considered when designing, setting the best feasible value.

(4) fuel spray nozzle hole diameter and number on the little curve shape influence of injection characteristics, but has a great influence on the cycle fuel injection quantity. Nozzle parameters should be combined with theoretical calculation and experiment results confirm, and further improve the discharge coefficient of orifice.

(5) the above-mentioned parameters on fuel injection characteristics influence are not isolated, but mutual restraint, in order to obtain the ideal fuel injection rate, in the design process in the injector also need comprehensive consideration, combined with theoretical analysis and test, the optimal combination of the parameters, the real machine test determines the optimal plan.

\section{REFERENCE}

[1] Xu Jialong for electronically controlled fuel injection technology of diesel [M].Beijing: China Communications Press, 2004:1 50

[2] Wu Jian, $\mathrm{Hu}$ Linfeng, $\mathrm{Li}$ Detao. Simulation of accumulator type injector fuel injection process analysis of [J]. internal combustion engine engineering, 2002,23 (4):15 20

[3]. Dong Yaoqing, Zhang Wanping, Gu Mengjun, et al. The engine, simulated with the [J]. common rail injection effect of system parameters on the performance of the diesel engine (2006, 5):23 30

[4]. Li Shaohe. High pressure common rail diesel engine electronically controlled hydraulic injector design and research. Huazhong University of Science and Technology, Wuhan, [Dissertation], 2004.4

[5]. Chiavola O, Gluianelli P. Modeling and Simulation of CommonRailSystems[C]. SAE Paper 2001-01-3183, 2001

[6]. tie Lin Jian, Wang Yang, Su Wanhua. Research on [J]. effect of design parameters on the performance of high pressure common rail diesel. 2001, 19(4):289 294

[7]. Huang Maoyang. The research and development of high pressure common rail diesel engine fuel injection system, and high speed solenoid valve structure and control parameters optimization and performance testing system. Southeast University, Nanjing, [Dissertation], 2005.4

[8]. An Shijie, Ouyang. Analysis of its main components characteristics of high pressure common rail fuel system. Small internal combustion engine and motor,2002, (1):41 44 